\title{
Transcendental Phenomenology: Overlooked Methodology for Marketing Research
}

\author{
Melissa M. Martirano ${ }^{1}$ \\ ${ }^{1}$ PhD Candidate, Northcentral University, Prescott Valley, AZ, USA \\ Correspondence: Melissa M. Martirano, Northcentral University, Prescott Valley, AZ, USA. E-mail: \\ mmartirano@njcu.edu
}

Received: April 1, 2016

Accepted: April 20, 2016 Online Published: May 24, 2016

doi:10.5539/ijms.v8n3p58

URL: http://dx.doi.org/10.5539/ijms.v8n3p58

\begin{abstract}
When marketing researchers select their methodology, two main choices are open to them: qualitative and quantitative. Quantitative has long been associated with scientific, empirical research based on statistics and numerical comparisons, considered by some marketing analysts to be objective and empirical. Qualitative methods are favored for "soft" social science and humanities research as a means to explore human opinions and perceptions through first-hand experience. Thus there has been a longstanding problem of pursuing qualitative research that is considered as free from bias and accurate as its quantitative counterpart. One philosopher who set out to imbue qualitative methodology with the same credibility given quantitative was Edmund Husserl, an early 1900s German philosopher. He developed transcendental phenomenology as a methodology that could explore experiences with the same objectivity as quantitative styles via surpassing the preconceptions of the researcher through use of a primordial fugue state called epoché. Although researcher would use qualitative tools such as interviews and questionnaires, inquiries would be formulated and analyzed free from preconceptions and bias, processed via bracketing of the most common responses. Husserl's writings were hard to decipher and not as readily adapted to research as other qualitative methods, including hermeneutic phenomenology, which includes researcher input. Nevertheless, if used properly, even for such unlikely-seeming research projects as those dealing with marketing, transcendental phenomenology can produce valid and reliable results yielding valuable information for philosophical purists capable of rigor and discipline.
\end{abstract}

Keywords: transcendental phenomenology, qualitative, quantitative, epoché, bracketing, Husserl

\section{Introduction}

In the 1960s, transcendentalism was connected with hippies, psychedelia, gurus and meditation. Close to a century before, it brought forth bucolic visions of communing with nature ala Thoreau and Whitman. It is odd, then, for this term to be connected with a very abstract, almost obtuse form of scholastic research. Thanks to Professor Edmund Husserl, who wrote in nearly incomprehensibly dense German prose, the concept of transcendental phenomenology became one choice in the arsenal of qualitative researchers, although a commonly overlooked one. For scholastic researchers, inquiry and understanding are inextricably linked. Students of marketing are both lucky and cursed because they must make a deliberate choice: whether to look into experiences and perceptions through qualitative methods, or perform empirical research involving quantitative methods of data compilation and analysis. Transcendental phenomenology has been long overlooked and sorely underutilized in marketing research. Developed by Husserl in the early to mid-1900s, this philosophical methodology diverged from traditional research methods, including other forms of phenomenology. Husserl set out to solve the following problem: how to design a qualitative methodological research study as objective and accepted as quantitative methodology studies. Like transcendentalism and transcendental meditation, its shelf-life appeared short. Nevertheless, this esoteric methodology can be successfully incorporated into marketing studies in a way that produces remarkably bias-free, credible results, as will be explained in this paper.

\section{Theoretical Aspects of Transcendental Phenomenology}

When conducting research from a context of phenomenology in general, the underlying dichotomy is how to connect with the essence of the topic's being through sources that are related by participants, yet imparted and laden with perceptions of both the source and the receptor. Owing to Cartesian ontological principles, this 
paradox stems from the nothing that anything which can be conceived is by definition extant (Borges, 2014). The $18^{\text {th }}$ century rationalist, Immanuel Kant (Bourges, 2014), however, understood the meaning of Descartes in terms of being bound to a presumptive movement starting with logic (ability to think thoughts) to an ontological context (if something can be thought, it must exist), invalidating his thesis. Kant argued that this submission to thought processing differs from undeniable proof that a thing exists. He posited that Descartes' thought reliance conditionally supported that something existed, or alternatively stated a precondition for cognition. Under this paradigm, thinking or conceptualizing anything is the initial point; deducing any type of existence at that point, whether metaphysical or ontological, would necessitate escaping the bonds of logic. For Kant, and later Husserl, cognition alone is incapable of assuring existence of its res (Latin for thing) or in Husserl's own terminology, dasein (German for the thing) (Husserl, 1931).

Accepting that cognition alone cannot guarantee something's existence, a quandary arises for all phenomenological researchers who require some objective component or phenomenon of research, such as recitation of experience that is objective in name while subjective in both recantation and reception. Paramount to this paradox is the nexus between subjective projection and objective reality of existence (Rawlings, 1952). Fathoming this juncture demands reliance on consciousness, according to modern interpreters of Descartes and Kant based on self-consciousness according to philosophical interpreters such as Fichte (Fisette, 1999). Under this conception, objective reality is required for subjective perception, which is itself inferred prior to initiating a study of a phenomenon or being in any area or field, including marketing. For example, as a marketing researchers elicits revelations that provide information about the marketing phenomena at issue, they are constrained by Kant's unequivocal basis on cognition as well as Husserl's contention that reality presents as dependent being (Husserl, 1931). Both cognition and perception limit non-transcendental phenomenologists attempting to discern understanding about the objective, without delving into the subjective (Rawlings, 1952). This may obstruct consideration or authenticate it, depending on one's reading of Husserl's philosophical and methodological approach to phenomenology known as transcendental (or sometimes psychological) phenomenology; this methodology prima facie demands departure from or transcendence beyond common definitions that compose traditional phenomenological methodology, conceptualizations and frameworks (Crowell, 2002). One can understand this by combining the works of Conklin (2005), Crowell (2006), and most formidably Thomasson (2007). When respondents describe experiences, they must utilize language with preconceived meanings; the researcher understands the description based on their own lingual connection.

Thus, in the fairy tale "The Princess and the Pea," listeners immediately understand what the cause of the princess's discomfort is: a small, round vegetable. If the princess insisted that she felt a "keedling" when she slept, no one would understand her, as a "keedling" is an unknown quantity. It is based on no relatable construct, is without context and exceeds both imagination and presupposition. Therefore such a term is meaningless within the framework of phenomenology, unless one is able of reaching Husserl's state of epoché and transcends preconceptions, reaching the primordial essence of the concept itself. Only then would the listener be able to process the information, in an arena of enforced philosophical solitude.

\section{Cognition and Transcendental Phenomenology}

Three cognitive types were present in Husserl's system: theoretical, axiological (connected with values) and practical (Husserl, 1931). All three had been vexing for pre-Husserlian phenomenological research in diverse manners. First, if a phenomena is theoretical, its existence is not absolute; if axiological it is subject to imposition of values from either the relator or the researcher; if practical, context in the extant world conveys meaning. In order to induce an unadulterated probing of phenomena, Husserl developed a method necessitating the researcher to completely disassociate with anything in existence and to and annihilate self-consciousness. This conundrum at first perplexed Husserl, because consciousness, dependent upon thought, cannot be eradicated by thought. The dilemma lies in the essence of consciousness as possessing absolute being; conversely that something exists means it is perceived or dependent on filtering through the conscious system of the thinker Madison, 2009). This enigma owes its genesis to Kant's and Descartes' emphasis on thought as require to create a link between the objective and the subjective reality of any particular thing or thought (Borges, 2014), and would seem to place upon Husserl the task of legitimizing objectivity's upon subjectivity and perception - the need for egoistic adulteration to reach the unperceived essence of any object or concept.

It is this juncture which distinguishes Husserl significantly from phenomenology in general, per Crowell (2002), this. Husserl transforms subjectivity beyond the prevalent egocentric stream of what the consciousness or cognition unravels. For him essence is an epiphany both intersubjective and communicative, which confers upon subjectivity embodiment and historical context in situ, without which Husserl cannot discern sense or sensibility. In a qualitative market research setting, the medium is words and the embodiment is the background or 
accoutrements inherent with subjective revelation (Crowell 2002). Husserl's transcendental phenomenology bequeaths on a phenomena novel appreciation or new ontology in conscious life.

According to Rawlings, Husserl essentially implemented a predictive procedure utilizing objective necessity of an object or phenomenon that is subjectively known (1952). This removes transcendental phenomenology from the arena of empiricism, which assumes the existence of concrete and universal realities or truths which can be derived, verified and retested with reliability and validity. Empiricism depends upon quantitative methods of data collection and analysis. Husserl's intention, per Tillman (1967) was to give academic credence to phenomenology, specifically transcendental phenomenology, as a recognized and accepted autonomous discipline that could provide results useable by scientists, particularly those concentrating in non-science subjects, such as marketing, as opposed to empiric inquiry. Husserl did this through imposition of philosophical constructs and mandates via non-inductive methodology that would expose experience absent experimentation, to determine how to close the gap between empirical scientific inquiry and conceptive logic. He was driven to legitimize in philosophical and methodology a method that would insinuate qualitative research as an efficacious tool for research that could not be successfully undertaken through the empirical scientific process, which might include some marketing studies. Rather than replace quantitative empiricism, Husserl augmented other methods, providing a compatible yet severable research form, not an alternative to other formats. Husserl's iteration and understanding is optimal, even mandated, to facilitate research of a topic unsuited for empirical scrutiny or experimental means to elicit understanding or resolution (Tillman, 1967).

That Husserl's philosophy and method are available where scientific empiricism would be inapplicable presupposes cognition as a precondition for a system of metaphysic understanding of a phenomenon, far overreaching the metaphysical bond to cognition (Crowell 2002). This characteristic exalts transcendental phenomenology well above the restrictions of empirical research, which is undertaken to support already enunciated hypotheses through scientific experimentation, data collection and scrutiny. In science, the results have been posited; in transcendental phenomenology they are open to possibilities. Husserl contribution was expansion of methodology by positing innumerable possibilities by elucidating normative categories of unassailable knowledge. Conversely the outcome of empirical science studies necessitate references to mediated reality that dictates only facts can follow from other facts. Husserl proffers an eidetic science, revealing the true essence of a phenomenon, and excluding the assimilation of theoretical results correlated to empiricism and scientism (Rawlings, 1952). Rawlings continued to explain that Husserl's eidetic description of thoughts was apart from logical deduction, and thus allowing the subject of study inherent selfhood, attained through grabbing and holding onto it in a primordial manner, devoid of the artificially-imposed mental constructs inherent in language articulation.

Thomasson (2007) addresses Husserl's underlying cognitive versus intuitive, pre-lingual paradox in her systematic analysis of the Kantian framework as adapted by Husserl. She argued that subjectivity itself constitutes the framework within which reality is understood; thus the transcendental phenomenologist must reject metaphysical realism and rely only on the eidetic construct of being, separate from the aforementioned Latin res or German dasein. That position correlates with the fundamental principle that transcendental phenomenology is not compatible with the outcomes of scientific research. Therefore, Thomasson rejected empiricism in this context, labeling it as more reflective of researcher bias than transcendental phenomenology (2007).

\section{Avoidance of Existentialist Tendencies}

Due to its suitability for qualitative research, the abundance of material presented to the transcendental phenomenologist enables one to posit the absolute essence, but does not require positing concrete existence (unless one counters with the Cartesian/Kantian definition that positing is akin to cognitively acknowledging, hence any form of perception presupposes substantively the existence of the objective). Again, Husserl avoided this challenge by turning to primordial intuition, circumventing the need for cognitive enunciation. Husserl does, nonetheless, admit the presence of profiles and perception (allowing for contamination by the ego and its attendant attained attachments) as inherently required in order to transcend phenomena to new levels of consciousness (Husserl, 1931). Thus, as identified by Crowell, Husserl presents an opportune cognitive detour enabling the researcher to arrive at philosophical insight void of presuppositions, centering on pure consciousness/essence (2006).

While qualitative in nature, transcendental phenomenology exceeds the scope of basic narrative research, as delineated by Creswell (2006). According to Creswell, qualitative research is well-suited to narrative information-gathering practices. This can present as either a text or discourse mode of inquiry in qualitative 
research. While there are basic similarities, especially in the early stages, between Creswell's qualitative narrative-based methodology and research grounded in experience-based but not limited transcendental phenomenology, there are distinctions. Transcendental phenomenology normally includes a cross-section of persons experiencing the same phenomenon rather than a small sampling. In the case of narrative research, Beatty elucidates that this conditions the experience in light of the single participant's personal goals, assumptions, and limitations, and may include involvement of the researcher's own personal goals and presuppositions as well. This is akin to the branch of phenomenology known as hermeneutic phenomenology, which includes and relies upon input, thoughts and analysis of the researcher (Creswell, 2006). Phenomenology that is labelled transcendental phenomenology attempts to ascertain the essence of constructs by removing researcher bias, a paramount distinction from other research forms, including other forms of phenomenology.

Simultaneously, this process acknowledges that individual recollections are limited hence not complete all the time (Beatty, 2014). Furthermore, Madison (2009) mirrors to some extent Crowell's findings that transcendental phenomenology is purposefully dependent upon passivity, in the form of the researcher's avoidance of interjecting presuppositions (2002) and Husserl's own statements concerning intentionality (1931) when he explains that experiences of phenomena are conscientiously assumed, but with uncertain outcome (as opposed to scientific empirical data which has a range of possible outcomes built in to the design of the research and experimentation). This underscores the concept that transcendental phenomenology is predicated on possibilities not certainties. Madison posits that existence is never a simple course that will directly proceed along a given path, but always entails an individual's strivings in order to realize potentials and possibilities. The outcome of experiences, he states, is dependent upon how individuals respond and resolve to be. Humans exist authentically when they heed their conscience, and assert responsibility and face up to consequences of their actions (2009). It is this authentic experience, unfiltered through any lens of researcher presuppositions or bias, which distinguishes transcendental phenomenology and sets it apart from other methods, including narrative research. In fact, this distinction imbues transcendental phenomenology with far greater possibilities than other methods, including both quantitative scientific research and qualitative narrative research or other phenomenology that includes researcher analysis.

\section{Transcendental Phenomenology Applied to Marketing Research}

Thus qualitative research, approached using the transcendental phenomenology methodology, provides for a result that transcends the narrative and analysis through a demystification accomplished by two major processes or functions inherent in Husserl's philosophy: Epoché and bracketing. Both are essential to recovering bias-free information that will reveal the true essence of the inquiries related to specific topics, such as marketing. During the preparatory phase of epoché, which is when researchers formulates questions for interviews, surveys or questionnaires, they "put away" prior conceptions to reach that pre-language state Husserl recognized as essential. By doing so, the researcher is uninvolved in the outcome, although Beatty (2014) conceded that some researcher will want to participate in the questions themselves, not as an analyst but as a responder. According to Conklin (2005), epoché allows researchers to apprehend themselves purely in the moment as ego, creating philosophical isolation, and involving use of this truly radical philosophy that creates an the strict philosophical solitude described above. Cartesian being-ness and scientific truth are excluded from the epoché state. This allows perception and psychological categorization and contextualization to be removed, so that knowledge is attained only through intuition and reflection, using the primordial or pre-language brain functioning. This will allow the passive receptivity necessary for subscribers of the transcendental phenomenological process to achieve viewing phenomena in a new way. It creates an opportunity for openness and receptivity to world experiences devoid of judgment or presuppositions. Marketing questions regarding brand preference or advertising media are approached with no preference, encouraging non-directed responses.

Following preparation of questions and asking them during a state of epoché cines the phase of bracketing, which is interactive. Nevertheless, within bracketing it also presuppositions, judgments, and biases must be put away through reduction. The transcendental phenomenologists take in information from participants mostly in narrative or responsive form, or via observation and artifacts. During reduction, Husserl significantly chose not to distinguish between being and knowing. This is due to what Tillman explains as the workings of bracketing as a temporary suspension in the belief that phenomenon being explored have actual being, that they exist as concrete, discrete objects of study. It allows researchers to focus on the essential trait or essence of the experience, without cluttering this focus with concern over beliefs of existence or perceptions (1967).

Without having to consider whether or not a phenomenon exists, the mind is freed to receive the pre-structural information from all sources, including intuition, in order to exclude extraneous information regarding that phenomenon. Thus with continued bracketing, or removal of non-essential constituents, a phenomenon is 
reduced further and further, until all that remains is its pure essence. This is the new world viewpoint of a phenomenon that Husserl's method produces which is unlike that obtained through any other method. It can only exist if the constructs usually imposed by researchers based upon their own presuppositions are eliminated through operation in epoché, and if researchers continually, thru eidetic reduction, reveal simpler pre-verbal experiences and values of construct that are mentally used to inform and create more complex conceptualizations and operations (Tillman, 1967). The residue left after bracketing or reduction is that primordial, pre-structured, pre-judgmental essence of the phenomenon, i.e., the pure form of being (Crowell, 2002). What Husserl has created through transcendental phenomenology is a schema of thought and observation unencumbered by the vestiges of later applications, hence endowed with rigorous perfection (Tillman, 1967). In some ways this resembles thematic analysis, but the basis is purely responses with no researcher input.

\section{Advantages of Epoché and Bracketing}

By these tools of epoché and bracketing transcendental phenomenology is able to surpass other forms of qualitative research in producing results concerning the true essence of the phenomenon being studied, such as areas in marketing concerning brand name importance, trustworthiness, and optimal marketing strategies. Hegel begat general phenomenology as a qualitative method to uncover pure reaches of cognitive expression, yet, Husserl surpassed Hegel.. He based this on modes of reflections, literally the most frequent responses to specific questions, which open up avenues to allow for increased understanding of the true nature of experience and phenomenon, free from outside disrupting forces such as preconceptions or analysis (Conklin, 2005). Rather than interpreting experiences using preconceived notions and explanations, transcendental phenomenology shifts the focus to the participants' experiences. Researcher insights are excluded at all phases, preparatory, executive and analysis. Through this system essence is revealed at the crossroads of experiential physicality and inner psychology of the respondent alone. In the intersection between these two strata, great understanding takes place. Objectivity meets subjectivity but without subjective burdens, and true essence is all that remains from reduction.

Conklin also used Husserl's terms "noesis" and "noema" to distinguish between cognition and essence (2005). In this sense, transcendental phenomenological research begins at the point of noesis. Noema is intentional but cannot be influenced by researchers, according to Conklin. Thus in marketing studies, consumers are the sole source of data and their responses dictate results, not researcher analysis (Conklin, 2005).

Responders may answer differently during various stages of interviews. These embellishments are not to be regarded as contradictions, but as fuller renditions that make possible true essence revelation. This requires flexibility of researchers, and also underscores a major difference between qualitative and quantitative methodologies. Studies performed by different researchers may not always yield identical results in the former, although they should in the latter. Conklin stated that such sifted is desirable and should be encouraged in qualitative research (2005).

Many researchers have avoided using transcendental phenomenology, despite its lack of bias and accuracy of results. Tillman speculated that this may stem from the fact that Husserl's philosophy is enunciated in language that is abstract, obscure and esoteric, basically not accessible and applicable to everyday life (Tillman, 1967), and was originally written in dense German and then translated. It has been cumbersome to put Husserl's theories into a methodology that embraces his intentions without inserting researcher bias diluting them by inclusion of techniques from other disciplines or approaches, and without making them so vague as to be meaningless. Experts in this area, such as Moustakas (1994) and Polkinghorne (1989), have produced a five-step procedure, similar to those produced by Creswell (2006) and others.

\section{Transcendental Methodology Process}

The steps are all necessary to produce a study that is true to Husserl's transcendental phenomenology philosophy and construct, and can be summarized as follows:

1) Identify the phenomenon to study. This means first selecting a topic, then parsing it to determine if it is best suited for qualitative or quantitative study. If it appears that the data obtained will not be the sort that is derived from repeatable experiments, but more that received from narrative recitations or observations of participants, then the researcher should be assured that a transcendental approach that does not involve analysis or bias on his or her part is optimal. Oftentimes, according to Creswell (2006), transcendental phenomenology is useful in research involving such fields as sociology, psychology, nursing, health sciences, education or any topic where the basic elements of the study will be the life experiences of the participants. This makes it ideally suited for marketing studies which seek preferences or perceptions from respondents. 
2) Create sense of epoché. This predicates utilizing tools for gathering data. During inquiry development, bracketing occurs, placing the researcher into an unbiased, pre-linguistic, pre-structured state within which the mind can freely absorb experiential information analysis-free.

3) Collect data from a sample of the population of persons who have experienced the phenomenon. Although this sample should be statistically significant in order to achieve saturation (the point at which answers become redundant) (Marshall, Cardon, Poddar, \& Fontenot, 2013), it should not be overwhelming, lest quality be sacrificed to save time or insure completion. Polkinghorne (1989) recommends samples as small as 5 to as large as 100 for interviews, depending on topic. For questionnaires, there are various formulae, such as that advocated by van Dessel, which can produce results that are within an acceptable margin of error while providing an academically desirable level of confidence, often around 95\% (Van Dessel, 2013).

4) Analysis phase but using response frequency free from bias. This is called horizontalization. Once significant statements or quotes are identified through bracketing, they are combined into themes, again without subjective input from the researcher. This is called clustering.

5) Development of textural description (what) and structural description (how), both derived from clustering and bias-free, revealing the ultimate essence of the experience or phenomenon, imparting insight without partiality. (Moustakas, 1994). Creswell explained such results of refining and bracketing as the essence of the phenomenon, which has non-transmutable, "invariant" structure (Creswell, 2005).

By following these steps, a researcher can produce a work that represents the standards set forth by Husserl in his transcendental phenomenology philosophy, about one or more issues in marketing that will be bias-free. This is what sets apart transcendental phenomenology, distinguishing it from virtually all other forms of research which in one respect or another insert researcher bias or analysis into the process. Yet despite the richness of its results, this methodology is often overlooked by marketing researchers, perhaps due to the obscurity of Husserl's terminology or just lack of familiarity with the process.

\section{Conclusion}

In summary, for those innovative enough to apply this methodology to marketing studies, the results will consist of unfettered revelation and reduction, and will be reliable. The researcher, however, must comply with Husserl's demanding conditions. This is a philosophy that had its birth in the phenomenology of Hegel, but was honed by Husserl into a unique process that yields results that reveal the true essence of a phenomenon. Insight is garnered through appreciation of this new, transcended view of something that otherwise is clouded by layers of extraneous components and distracting presuppositions. What Husserl has defined is a qualitative method that is stripped of researcher input, and produces a result that is the core and essence of the object of study, tailor-made for philosophical purists willing to embark on a lesser used methodology that yields uncontaminated fruits of discovery.

\section{References}

Beatty, J. (2014). Everyday Phenomenology and an Exploration of "the Transcendental Attitude". Organization Management Journal, 11, 114-115. http://dx.doi.org/10.1080/15416518.2014.940265

Bourges, M. (2014). Hegel and Kant on the Ontological Argument. Modern Philosophy. Retrieved from https://www.bu.edu/wcp/Papers/Mode/ModeDeLo.htm

Conklin, T. (2005). Method or Madness: Transcendental Phenomenology as Knowledge Creator. iiqi.org. Retrieved from http://www.iiqi.org/C4QI/httpdocs/qi2005/papers/concklin.pdf

Creswell. (2006). Qualitative Inquiry and Research Design. Thousand Oaks: Sage Publications.

Crowell, S. (2002). The Other Husserl: The Horizons of Transcendental Phenomenology. Journal of the History of Philosophy, 40(1), 132-133. http://dx.doi.org/10.1353/hph.2002.0006

Fisette, D. (1999). Husserl et Fichte: Remarques sur l'apport de l'idealisme dans le Developpement de la Phenomenologie. Symposium, III, 185-207. http://dx.doi.org/10.5840/symposium19993219

Husserl, E. (1931). Ideas: General Introduction to Pure Phenomenology. New York: Routlege.

Madison, G. (2009). Transcendental Phenomenology: A Practical Philosophy. Santalka: Filosofija, 17(3), 17-28. http://dx.doi.org/10.3846/1822-430X.2009.17.3.17-28

Marshall, B., Cardon, P., Poddar, A., \& Fontenot, R. (2013). Does smaple size matter in qualitative research?: A review of qualitative interviews in IS research. Journal of Computer Information Systems. http://dx.doi.org/10.1080/08874417.2013.11645667

Moustakas, C. (1994). Phenomenological research methods. Thousand Oaks: Sage Publications. 
Polkinghorne, D. E. (1989). Phenomenological research methods. In R. S. Valle \& S. Halling (Eds.), Existential-phenomenological perspectives in psychology (pp. 41-60). New York: Plenum Press. http://dx.doi.org/10.1007/978-1-4615-6989-3_3

Rawlings, F. (1952). Transcendental Phenomenology. Nature, 170, 470-471. http://dx.doi.org/10.1038/170470a0

Thomasson, A. (2007). In What Sense is Phenomenology Transcendental? The Southern Journal of Philosophy, $X L V, 85-92$. http://dx.doi.org/10.1111/j.2041-6962.2007.tb00114.x

Tillman, F. (1967). Transcendental Phenomenology and Analytic Philosophy. Husserl Symposium, III, Vassar College, 31-40. http://dx.doi.org/10.5840/ipq1967711

Van Dessel, G. (2013). How to Determine Population and Survey Size. Checkmarket. Retrieved from https:/www.checkmarket.com/2013/02/how-to-estimate-your-population-and-survey-sample-size/

\section{Copyrights}

Copyright for this article is retained by the author(s), with first publication rights granted to the journal.

This is an open-access article distributed under the terms and conditions of the Creative Commons Attribution license (http://creativecommons.org/licenses/by/3.0/). 